\title{
Game-based Learning for Digital Natives: Knowledge is Just a Click Away
}

\author{
Kathrin Knautz ${ }^{1}$, Simone Soubusta ${ }^{1}$, Lisa Orszullok ${ }^{1}$ \\ ${ }^{1}$ Department of Information Science, Heinrich-Heine-University Duesseldorf, Germany
}

\begin{abstract}
In this paper, we present a project in which a university course on knowledge representation is turned into an interactive online text adventure. Our new way of using game mechanics demands a comprehensible didactic design during the planning phase as well as during the implementation of the course and the whole project. To ensure this, we have worked with storyboards.
\end{abstract}

Keywords: Game-based Learning; Gamification; Storyboard; Digital Natives; Information Literacy Instruction; Flow

\section{Raising Student Engagement through Gamification}

Games have been experiencing something of a renaissance in recent years. Of course, playing has always been a natural instinct for humans [1]. From the moment we are born we have this instinct to play. It diminishes, unfortunately, as we grow older, but never disappears completely. With the digital age, video games in particular have done quite a lot to make playing games popular.

The reason that people spend so much time playing games is that gaming often causes the so-called flow experience [2]. Flow is a mental state of intense concentration where work seems effortless and that we can reach at the sweet spot between challenge and skill utilization.
This has the effect that gamers manage to solve frustrating challenges, master difficult tactics and spend hours improving their skills at a particular game. The hard work and concentration that people put into gaming are nothing less than astounding. For this reason, people have been trying to emulate certain aspects of games in order to profit from some of these positive aspects. This process is called gamification and describes the use of game mechanics in non-playing contexts [3]. The game mechanics increase motivation and engagement by satisfying human desires like the desire for rewards and status, for achievement and competition.

Gamification is also already being employed in the realm of education [4-6], which inspired us for our own project: turning a 2nd semester course on knowledge representation into a kind of interactive online text adventure. It stands to reason that today's generation of students - the digital natives [7] -, which has grown up in an environment dominated by technology, ought to be accommodated in this way.

\section{The Project: Turning a University Course into a Game}

In order to engage students in the area of information literacy and to make the didactic design of the university module "knowledge representation" [8] explicit, we have brought together two compo- 
nents: storyboards and game mechanics. The design and implementation of the course and online platform for the undergraduate students was done within a university master course.

Storyboarding: In order to plan this project effectively with students, we have used a combination of the storyboard concept as shown in [9] and the classic storyboarding as a creative technique.

The former is an approach to anticipate, plan and control didactic designs in educational environments. The idea of representing, processing and refining didactic knowledge through simplicity, clarity and visual appearance is an important factor.

According to Jantke \& Knauf [10] "[a] Storyboard is a nested hierarchy of directed graphs with annotated nodes and annotated edges. Nodes are scenes or episodes; scenes denote leaves and episodes denote sub-graphs. Edges specify transitions between nodes. Nodes and edges have (pre-defined) key annotations and may have free annotations". Figure 1 shows the components used. The key annotations proposed by Jantke and Knauf have been added in this project with elements of games and classical storyboarding.

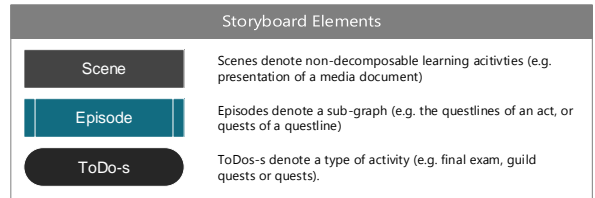

Fig. 1: Used storyboard elements.

The need for this arises from the fact that all content of the course has been implemented not only as an e-learning platform, but additionally with the help of the indicated game mechanics and an epic story. Supplementary (key) annotations are for example "Available Points", "Available Achievements", "Story Key Points", "Act" etc.
Game mechanics: Implementing gamebased mechanics in an educational environment gives us the opportunity to engage students, motivate action and drive participation. The game mechanics used in this project are experience points (XP), levels, achievements, leaderboards, challenges and virtual goods. It is essential in this project to reward students for correct problem solutions and to give them a constant overview of their skills and knowledge. Some of the game mechanics that are used will be described in the following.

In the beginning, students choose a race (elves, goblins, orcs or humans). As players they can level up to level 15 . Reaching level 11 is required to pass the course, higher levels grant an additional bonus. However, the effort and work required to reach level 14 doubles in comparison to the requirements for level 11 . By solving quests students accumulate XP. Once they have collected enough XP, their character will level up. The accumulation of points can serve as positive reinforcement to motivate students to initiate further tasks. An analysis of point distribution and quest status allows teachers to detect knowledge deficits of students and retarget problematic topics. Furthermore, high-achieving students benefit from special and more difficult tasks in so called side quests.

Students can also win achievements, which constitute a sort of trophy. Overall, 75 achievements and meta-achievements are available for the students. Some of them are unique, other are only accessible by meeting special visible or secret requirements like solving a special quest in the first try.

The leaderboard is a high-score table visualizing the point distribution of the special guild quests (group quests). Guild quests are a kind of competition where the guilds have to challenge each other to win XP. By tracking und displaying the 
student's actions, human desires like competition and status are satisfied.

\section{Game Description: Legend of Zyren}

With the help of storyboards it was possible to create an interesting story, challenging tasks and an educational entertainment. The whole project, called Legend of Zyren, has been implemented on an e-learning platform as a visual text adventure that focuses on puzzles. It is completely written in PHP and administered in a MySQL database. Most of the implemented graphics were made by a graphic designer.

The form of interactive fiction that is used consists predominantly of narration, minimal gameplay and multiple storylines. Besides these characteristics the game mechanics described earlier are implemented as well.

After choosing a race, the adventure in the land of Zyren begins. There the student embark to find the legendary book of knowledge which has long been lost. The adventure is divided into four acts - each covering about a quarter of the subject matter and each taking place in a different part of the country. Through the power of the collective knowledge anyone who owns the book is able to gain control over the whole realm of Zyren. As the book had been split into four pieces after a war, the protagonist departs on a mission to discover all of the missing parts and reveal the secret of its power. His journey leads him through the four areas of Zyren, the camps of the orcs, the forests of the elves, the cities of the humans and the mines of the goblins, which each hide one part of the book. Through the course of the story, the protagonist encounters many dangers and challenges in the form of interactive tasks in which he has to prove his knowledge. There are main quest lines which deal with the search for the book and are obligatory for students to do in order to complete the course. Additionally, there are many side quest lines, which are miscellaneous quests that deviate from the main plot. The tasks of the side quests take up the issue of the main quests but are more challenging. Overall 153 quests are implemented which comprise drag \& drop tasks, multiple choice items, crosswords, fill-in-theblank-texts, free essays, each of them representing a different approach to convey information literacy.

At this time 150 students - divided into 3 groups - interact on the platform and in the practical labs. A principal investigator, five group leaders and twelve tutors supervise the platform, answer questions, review the contents of the lecture and organize interactive guild quests in the practical lab.

\section{Visualizing Didactic Design Using Storyboarding in a Game-based Educational Environment}

In this section we present the results from the symbiosis of game mechanics and storyboarding. Starting at the top level, we go deeper into the various sub-graphs. Towards the end we show the realization of an exemplary record of a game-based story(board) map.

The graph in figure 2 shows the top level storyboard. The module consists of two parts: 1. a lecture which teaches the subject matter; and 2. the game-based course with its online platform.

The right part of the graph shows different topics of the classical lecture as consecutive episodes. The episodes denote a sub-graph with the relevant subsections. The subsections in turn are scenes and refer to the corresponding lecture slides. The left side of the graph shows the correspondence of the lecture topic to the story in 4 acts. The participation in this experimental game-based seminar is voluntary and therefore repre- 
sented by dashed lines. All acts are episodes like the lecture topics and thus refer to their sub-graphs.

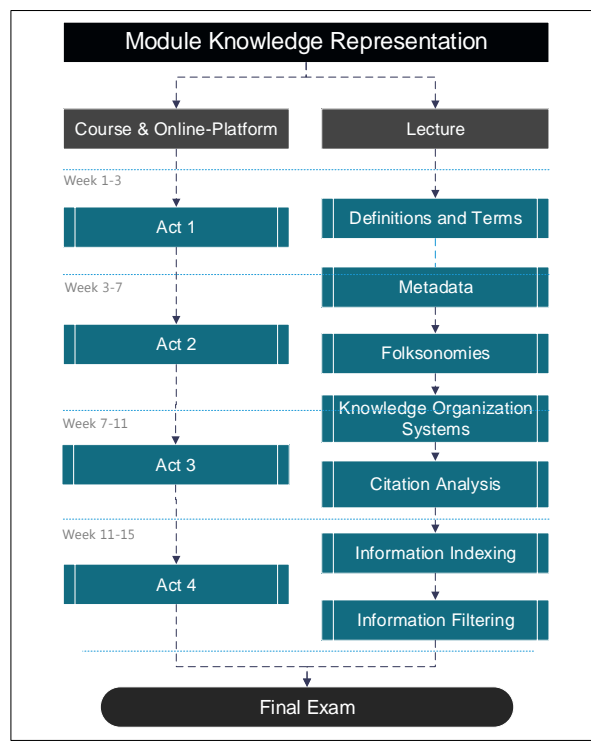

Fig. 2: Storyboard Knowledge Representation.

Figure 3 shows how a sub-graph of such an act looks. Each act is divided into two areas:

- an online platform where the majority of the game takes place and where students solve exercises or embark on adventures and

- a practical lab where questions are answered, the material is reinforced and where students can solve some tasks (guild quests) in groups, thus making the lab part of the game.

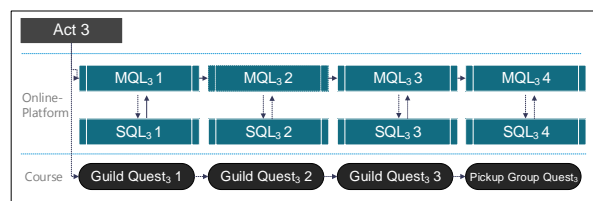

Fig. 3: Storyboard Act 3.

Each act comprises four main quest lines and four side quest lines, which are labeled as episodes. The main quest lines are linear and obligatory for students to complete. Additionally, there is the opportunity to solve more tasks in side quest lines.

These are entirely optional, but help to reinforce and enhance students' understanding. In this manner it is possible to receive extra points and achievements. In addition to the functions within the online platform there was still a need for defining special group tasks.

The structure of the various quest lines can be seen (figure 4) by accessing their sub-graph. Each quest line has a different number of text scenes and quests.

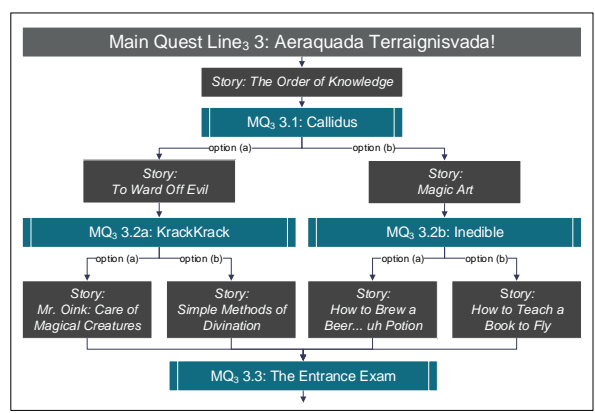

Fig. 4: Storyboard Main Quest Line 3 in Act 3 (excerpt).

Throughout the text adventure, students discover differing stories, plots and tasks based on their choices. The quests themselves are episodes and denote a sub-graph with task description, points and feedback mechanism. All quests are repeatable in order to allow students to experiment with various approaches to solve the given tasks.

Besides the usual graphical representation of the acts and quest lines (figure 24), it provides an implementation of the displayed contents as a game-based storyboard map. Here the four acts and their quest lines will be represented on the map of the game. A click on a quest line on the map opens an overview of the various quests within that quest line. Side quest lines form optional points on the map and go off on dotted paths from the normal way (figure 5). 


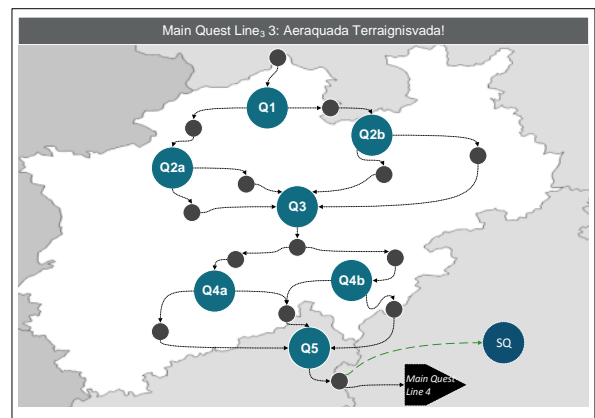

Fig. 5: Storyboard Map Main Quest Line 3 in Act 3

\section{Summary \& Outlook}

Traditional educational concepts relegate playing to the leisure time of students. A look insight the field of game studies and learning theory shows that effective learning is firmly connected to playing. In this paper we tried to connect the different characteristics of storytelling, learning and gaming approaches. The Legend of Zyren is a visual text adventure composed of exercises and static graphic features set in a narrative framework, which aims to teach information literacy with the help of game mechanics. The use of game mechanics in educational environments provides the opportunity to make learning more interesting, to arouse curiosity and thus to successfully provide essential knowledge.

For planning and final realization of such a project it is essential to represent the didactic design explicitly. Working with storyboards is an appropriate method in this context: they generate a plan of action, provide an overview of the information and can be used as a game-based story (board) map.

Unfortunately, not all implemented game mechanics and storyboard features are described here but we gave an insight on how game-enhanced learning can be implemented in combination with story- boarding in the context of a university course.

The course "game-based knowledge representation" will take place in the upcoming months. Extensive evaluation will be carried out subsequently.

\section{References}

[1] J. Huizinga, Homo Ludens. A Study of the Play Element in Culture, Routledge \& Keagan Paul, London, 1949.

[2] M. Csíkszentmihályi, Flow: The Psychology of Optimal Experience, Harper Perennial, New York, USA, 1991.

[3] G. Zichermann, and C. Cunningham, Gamification by Design, O'Reilly Media, Sebastopol, CA, USA, 2011.

[4] L. Sheldon, The Multiplayer Classroom. Designing Coursework as a Game, Course Technology, USA, 2010.

[5] http://q21.org/

[6] http://www.khanacademy.org/

[7] M. Prensky, Digital Game-based Learning, McGraw-Hill, New York, USA, 2001.

[8] K. Knautz, "Gamification im Kontext der Vermittlung von Informationskompetenz", In Informationskompetenz in der Schule. Ein informationswissenschaftlicher Ansatz, pp. 223-257, 2013.

[9] K. P. Jantke, and R. Knauf, "Didactic Design Through Storyboarding: Standard Concepts for Standard Tools", In Proc. of the 4th International Symposium on Information and Communication Technologies, pp. 2025, 2005.

[10] K. P. Jantke, and R. Knauf, "Storyboarding for Playful Learning", In Proc. of World Conference on ELearning in Corporate, Government, Healthcare, and Higher Education, pp. 3174-3182, 2006. 